\title{
Bullying and Cyberbullying Victimization and Weapon Carrying: A 3-Step Latent Class Analysis with a Covariate and a Distal Outcome
}

\author{
Diana Mindrila \\ University of West Georgia, USA
}

\begin{abstract}
The current study identified latent classes of victimization based on the prevalence of different forms of bullying and cyberbullying victimization experienced by 4,933 U.S. adolescents (ages 12-18) who took the 2013 School Crime Supplement of the National Crime Victimization Survey. Latent class analysis (LCA) with school behavior management as a covariate and reports of weapon carrying as a distal outcome differentiated four groups of adolescents who experienced a) mostly face-to-face bullying victimization $(C 1, N=497), \quad b)$ mostly cyberbullying victimization $(C 2, N=114)$; c) minimal or no bullying or cyberbullying victimization ( $C 3$, $N=4,257)$; and d) critical levels of both bullying and cyberbullying victimization $(\mathrm{C} 4, \mathrm{~N}=67)$. More effective behavior management at school significantly increased the probability of membership to latent classes with lower levels of victimization. Further, in reference to $C 3$, members of $C 1$ and $C 4$ were approximately $20 \%$ more likely to carry weapons to school.
\end{abstract}

\section{Introduction}

Bullying continues to be an issue of importance to educators, school psychologists, counsellors, criminal justice practitioners, school districts, and parents. With the introduction of new technology and access to social media, a new form of aggression, cyberbullying, has emerged [1]. Cyberbullying involves the use of information and communication technologies such as e-mail, cell phone and pager text messages, instant messaging, websites, etc. to support deliberate, repeated hostile behaviour by an individual or group [2]. Approximately 28\%, of U.S. students, ages $12-18$, reported being bullied at school or during the school year, and $9 \%$ reported being cyberbullied anywhere, including school [3]. Further, approximately half of the cyber-victims reported knowing the bully from school [4].

Recently, in the United States, there have been many wide-spread media reports of death and suicide that have involved various cyberbullying behaviours, affecting communities, school systems, and families. Further, bullying was linked to extreme cases of school violence, such as school shootings $[5,6,7]$. In fact, the stated principle motive of school shooters was obtaining revenge for being teased or ridiculed [8].

To facilitate the prevention and early identification of bullying and cyberbullying victimization, professionals dealing with youth must be aware of the most prevalent types of bullying and cyberbullying victimization. The current study aimed to 1) identify latent classes of victimization based on the prevalence of different forms of bullying and cyberbullying experienced by U.S. adolescents; 2) examine the relationship between the probability of bullying and cyberbullying victimization and behaviour management at school; and 3) estimate the probability of bringing weapons to school across latent classes of bullying and cyberbullying victimization.

\section{Literature Review}

Approximately 28\%, of U.S. students, ages 12-18, reported being victimized at school or during the school year, and 9\% reported being cyber-victimized anywhere, including school [3]. Further, approximately half of the cyber-victims reported knowing the bully from school [4]. Multiple studies suggest that the line between cyber-victimization and traditional victimization is not distinct; many cybervictims are also victimized in traditional environments [9, 10]. Cyber-victimization is not a problem that stays in the cyber-world; instead, it is often intertwined with more traditional forms of victimization. Bilić et al. [9] summarized the relationship between cyber- and traditional victimization as part of "cycles of violence transferred from school to the virtual environment and vice versa" (p. 27).

Cyber-victimization can occur inside and outside of the normal school hours, many times anonymously, and can involve many participants because of its global nature. This form of victimization can be far more insidious than traditional victimization, because there is no escape from it [11]. Students who have been both cyberbullies and cyber-victims suffer the most harmful effects of this phenomenon, such as, depreciation of the grade point average, fear, anxiety, depression and other psychological harm [4, 12]. Schoffstall \& Cohen [13] showed that students who engaged in cyber-aggression had higher rates of loneliness, and 
lower rates of social acceptability, peer optimism, number of mutual friendships, popularity, and global self-worth. Further, engagement in cybervictimization is often associated with problem behavior, depressive symptomatology, poor parentchild relationships, delinquency, and substance use $[14,15,16]$.

\subsection{Traditional Victimization and Cyber- Victimization}

Literature on school victimization describes a pattern of individuals who are victimized in cybersettings to also be victimized in traditional environments [17]. Multiple studies show the connection between cyber-victimization and traditional victimization; students who are exposed to traditional victimization are more likely to be victimized online, and traditional victimization often precedes cyber-victimization [18, 19].

Current research indicates that face-to-face victimization and cyber-victimization trigger cyberaggression and cyber-bullying [20]. This maladaptive coping strategy stems from the victims' feelings of anger and frustration and desire for revenge [21]. Similarly, peer rejection, as a source of strain, was positively associated with face-to-face aggressive behavior [22]. Research showed that adolescents who feel rejected experience enduring patterns of victimization [23]. Both cybervictimization and peer rejection were related to relational and verbal cyber-aggression [24].

The associated effects of victimization in multiple contexts aggravates social problems for victims and increases problems for educators who must deal with victimization at school as well as victimization that occurs in other environments [25]. Thus, as Fredstrom et al. suggested, psychosocial and adjustment difficulties are best examined through viewing victims in multiple contexts, not as victims of a single form of bullying [25].

\subsection{The Role of School Climate and Behavior Management}

Studies have shown that a positive school climate is associated with fewer incidents of victimization in schools. Allen [26] examined extant literature on bullying victimization in relation to school environment, classroom management, and teacher practices and found that harsh discipline methods and disorganized classrooms or school settings can lead to increased likelihood of bullying victimization. Other studies suggest that healthy school climates, including consistent discipline plans and a climate of respect for diversity, are associated with lower levels of student involvement with risky behavior such as victimization and weapon carrying [27].
As indicated above, research on victimization in the school setting focused on describing the forms, prevalence, and severity of this phenomenon, on investigating its psycho-social consequences, as well as on identifying the factors that might reduce the likelihood of its occurrence. More recently, researchers also focused on the development of victimization typologies, which aim to differentiate different forms of victimization. Such classification systems indicate the specific characteristic of each category of individuals and facilitate the early identification of victims in the school setting.

\subsection{Typologies of Victimization in the School Setting}

Several researchers aimed to develop typologies of school victimization and to identify the psychosocial characteristics of the identified types. For instance, Nylund, Muthén, Nishina, Bellmore and Graham [28] used latent class analysis to identify victimization patterns among middle school students and distinguished three victim classes: a) "victimized," b) "sometimes victimized," and c) "non-victimized." These groups differed in the degree of victimization rather than the type of victimization (physical versus relational). A variable measuring depressive symptoms was included in the latent class model as a distal outcome. Results showed that, with the exception of sixth grade, average depression scores were lowest for the nonvictimized groups and increased for classes with higher degrees of victimization.

A similar study, conducted by Want, Iannotti, Luk, \& Nansel [29] investigated the co-occurrence of five types of victimization among adolescents and identified a three-class model. One class experienced all types of victimization, another class experienced mostly verbal/relational types of victimization, whereas the third class had minimal victimization experience. Individuals included in classes with higher levels of victimization reported more depression, medicine use, injuries, sleeping problems and nervousness.

Another study conducted by Bradshaw, Waasdorp \& O'Brennan [30] examined ten different forms of victimization among middle school and high school students. With middle school students, the authors identified four victimization types: a) Verbal and Physical, b) Verbal and Relational, c) High Verbal, Physical, and Relational, and d) Low Victimization/Normative. With the exception of the Verbal and Physical type, the same types were identified with high school students. Cybervictimization, and sexual comments/gestures were the only types of victimization that did not have a lower prevalence in high school.

The current study extended this line of research by identifying distinct forms of victimization based 
on both face-to-face victimization and cybervictimization. Further, the study examined the relationship between individuals' assignment to specific victimization types and observed variables such as behavior management at school and the probability of carrying weapons to school.

\section{Method}

Data for the current study were collected by the U. S. National Center for Education Statistics (NCES) and the Bureau of Justice Statistics using 2013 School Crime Supplement (SCS) of the National Crime Victimization Survey (NCVS). NCES households are selected using a stratified, multistage cluster sampling design. 5,857 The SCS is administered to all eligible respondents ages 12-18 within NCVS households. A total of 5,008 adolescents completed the SCS [31]. From this sample, individuals without any missing responses on selected variables were included in the current study. The resulting sample included 4,933 individuals. In 2013, the SCS unweighted item response rates exceeded $85 \%$; on the majority of items, the response rate was $95 \%$ or higher [9]; therefore, no explicit imputation procedure was used to correct for item nonresponse. The SCS sample weights, which are a combination of household-level and person-level adjustment factors [32], were applied to the variables used in this study to avoid bias in standard errors and point estimates [33]. The SCS variables used in this study consisted of a set of binary items ('No'=0, 'Yes'=1) which asked participants whether a) they experienced different forms of bullying or cyberbullying; b) their school implemented effective behavior management strategies; and c) they brought a gun or other weapons to school or onto the school grounds during the current school year. The proportions of "yes" responses were calculated for fourteen binary survey items measuring different forms of bullying (bul1bul7) and cyberbullying (cyb1-cyb7). These descriptive analyses helped identify the prevalence of different forms of bullying and cyberbullying among the 2013 SCS respondents.

Latent class analysis (LCA) was conducted using the Mplus 7.4 software; this procedure is a special case of mixture modeling, which explains the relationships between observed indicators and latent categorical variables by classifying individuals into categories [34]. In the current study, a set of fourteen binary observed indicators measuring bullying and cyberbullying experiences (bul1-bul7 and cyb1cyb7) were used to specify a categorical variable (C). The hypothesized model also included behavior management as a covariate (bm) and weapon carrying as a distal outcome (weapon) of C (Figure $1)$; bm and weapon were composite standardized scores obtained by summing up responses on variables bm1-bm5 and w1-w3 respectively.

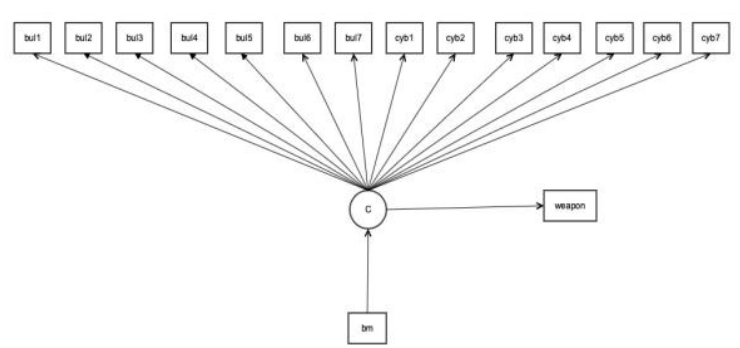

Figure 1. Latent class model with fourteen observed indicators, a covariate and a distal outcome

LCA was conducted using the 3-step approach proposed by Asparouhov and Muthén [35]. The traditional 1-step approach (estimating the entire model at once) is problematic because the inclusion of a distal outcome may lead to changes in group membership. Asparouhov and Muthén [35] proposed a new 3-step method which aims to correct for classification error. In the current study, this approach consisted of the following steps: (a) estimating the LCA model; (b) creating a nominal most likely profile variable $\mathrm{N}$; and (c) using a mixture model for $\mathrm{N}, \mathrm{C}$, weapon, and bm, where $\mathrm{N}$ is a $\mathrm{C}$ indicator with measurement error rates prefixed at the misclassification rate of $\mathrm{N}$ (Figure 2).

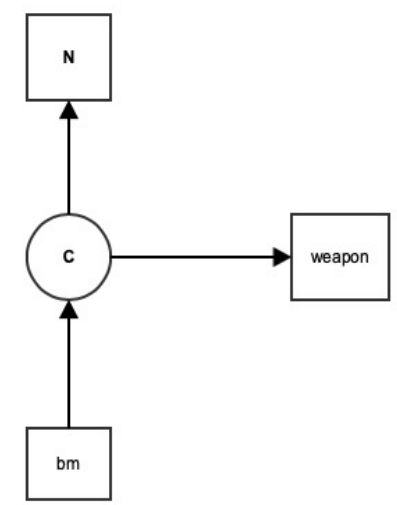

Figure 2. Mixture model with $\mathrm{N}$ as a nominal observed indicator, bm as a covariate, and weapon as a distal outcome of $\mathrm{C}$

Models with two (Model 2), three (Model 3), four (Model 4), and five (Model 5) latent classes were estimated. The optimal solution was selected based on the interpretability of the class centroids, hit rates (the percentage of correct classifications), entropy, and goodness of fit indices. Hit rates are indices of classification certainty and reflect the percentages of correctly classified cases [36]. Entropy is an omnibus measure of classification precision and shows how well a model predicts class memberships [36], or how distinct classes are from one another [37]. Entropy values range from 0 to 1 , 
Table 1. Proportions and Counts for Binary Observed Variables

\begin{tabular}{clrr}
\hline \hline Variable & Item & "Yes" Responses \\
\cline { 2 - 4 } & & $\%$ & $\mathrm{~N}$ \\
\hline & During this school year, another student has... & \\
\hline BUL1 & $\begin{array}{l}\text { made fun of you, called you names, or insulted you, in a hurtful } \\
\text { way? }\end{array}$ & $13.5 \%$ & 668 \\
& spread rumors about you or tried to make others dislike you? & $13.2 \%$ & 650 \\
\hline BUL2 & threatened you with harm? & $3.8 \%$ & 188 \\
\hline BUL3 & pushed you, shoved you, tripped you, or spit on you? & 293 \\
\hline BUL4 & tried to make you do things you did not want to do? & 108 \\
\hline BUL5 & excluded you from activities on purpose? & $2.9 \%$ & 216 \\
\hline BUL6 & destroyed your property on purpose? & $4.4 \%$ & $1.5 \%$ \\
\hline BUL7 & posted hurtful information about you on the Internet? & $2.9 \%$ & 141 \\
\hline CYB1 & purposely shared your private information, photos, or videos on & $0.9 \%$ & 45 \\
\hline CYB2 & the Internet or mobile phones, in a hurtful way? & $0.9 \%$ & 46 \\
\hline CYB3 & threatened or insulted you through email? & $2.1 \%$ & 104 \\
\hline CYB4 & threatened or insulted you through instant messaging or chat? & $3.2 \%$ & 156 \\
\hline CYB5 & threatened or insulted you through text messaging? & $1.5 \%$ & 74 \\
\hline CYB6 & threatened or insulted you through online gaming? & $0.9 \%$ \\
\hline CYB7 & purposefully excluded you from online communications? & 46 \\
\hline \hline
\end{tabular}

Table 2. Goodness of Fit Indices

\begin{tabular}{lcccc}
\hline \hline & $\begin{array}{c}\text { Model 2 } \\
\text { (2 Classes) }\end{array}$ & $\begin{array}{c}\text { Model 3 } \\
\text { (3 Classes) }\end{array}$ & $\begin{array}{c}\text { Model 4 } \\
\text { (4 Classes) }\end{array}$ & $\begin{array}{c}\text { Model 5 } \\
\text { (5 Classes) }\end{array}$ \\
\hline Akaike (AIC) & 16572.536 & 16201.264 & 16051.559 & $\mathbf{1 5 9 7 5 . 1 6 5}$ \\
\hline Bayesian (BIC) & 16767.647 & 16500.434 & 16454.788 & $\mathbf{1 6 4 8 2 . 4 5 4}$ \\
\hline Sample-Size Adjusted BIC & 16672.318 & 16354.262 & 16257.774 & $\mathbf{1 6 2 3 4 . 5 9 7}$ \\
\hline Entropy & 0.914 & 0.905 & $\mathbf{0 . 9 1 6}$ & 0.831 \\
\hline \hline
\end{tabular}

Table 3. Classification Probabilities for the Most Likely Latent Class Membership (Column) by Latent Class (Row)

\begin{tabular}{lcccc}
\hline \hline & $\mathrm{C} 1$ & $\mathrm{C} 2$ & $\mathrm{C} 3$ & $\mathrm{C} 4$ \\
\hline $\mathrm{C} 1$ & $\mathbf{0 . 7 8 2}$ & 0.017 & 0.194 & 0.007 \\
\hline $\mathrm{C} 2$ & 0.164 & $\mathbf{0 . 7 2 6}$ & 0.080 & 0.030 \\
\hline $\mathrm{C} 3$ & 0.004 & 0.001 & $\mathbf{0 . 9 9 6}$ & 0.000 \\
\hline $\mathrm{C} 4$ & 0.165 & 0.055 & 0.000 & $\mathbf{0 . 7 8 0}$ \\
\hline \hline
\end{tabular}

Table 4. Average Latent Class Probabilities for Most Likely Latent Class Membership (Row) by Latent Class (Column)

\begin{tabular}{lcccc}
\hline \hline & $\mathrm{C} 1$ & $\mathrm{C} 2$ & $\mathrm{C} 3$ & $\mathrm{C} 4$ \\
\hline $\mathrm{C} 1$ & $\mathbf{0 . 8 9 7}$ & 0.045 & 0.033 & 0.025 \\
$\mathrm{C} 2$ & 0.082 & $\mathbf{0 . 8 6 2}$ & 0.020 & 0.036 \\
$\mathrm{C} 3$ & 0.026 & 0.003 & $\mathbf{0 . 9 7 2}$ & 0.000 \\
$\mathrm{C} 4$ & 0.059 & 0.060 & 0.000 & $\mathbf{0 . 8 8 1}$ \\
\hline \hline
\end{tabular}


Table 5. Tests of Categorical Latent Variable Multinomial Logistic Regressions Using the 3-Step Procedure

\begin{tabular}{lrrrcc}
\hline \hline & Estimate & S.E. & $\begin{array}{c}\text { Estimate } \\
\text { /S.E. }\end{array}$ & Two-tailed p value & Odds ratio \\
\hline Parameterization using Reference C4 & & & & & \\
C1 ON BM & 0.632 & 0.198 & 3.191 & $\mathbf{0 . 0 0 1}$ & 1.881 \\
C2 ON BM & 0.746 & 0.235 & 3.175 & $\mathbf{0 . 0 0 1}$ & 2.109 \\
C3 ON BM & 1.050 & 0.194 & 5.412 & $\mathbf{0 . 0 0 0}$ & 2.858 \\
Parameterization using Reference C3 & & & & \\
C1 ON WEAPON & 0.202 & 0.047 & $\mathbf{4 . 3 3 7}$ & $\mathbf{0 . 0 0 0}$ & 1.224 \\
C2 ON WEAPON & 0.174 & 0.093 & 1.861 & 0.063 & 1.190 \\
C4 ON WEAPON & 0.184 & 0.065 & $\mathbf{2 . 8 4 0}$ & $\mathbf{0 . 0 0 5}$ & 1.202 \\
\hline \hline
\end{tabular}

Note: Values significant at the .05 level are marked in boldface.

where higher values indicate better class membership prediction [38].

The fit indices used to determine how well the model fit the data were the Akaike Information Criteria (AIC) and the Bayesian Information Criteria (BIC). Lower AIC/BIC values indicate a better model fit and higher model parsimony (achieving an acceptable model fit with the minimum number of classes) [38, 39].

\section{Results}

As indicated in Table 1, the most prevalent forms of bullying were being made fun of, being called names or insulted in a hurtful way $(13.5 \%)$ and being the subject of rumors $(13.2 \%)$. The least frequent forms of aggression were being purposefully excluded from online communications $(0.9 \%)$, being threatened or insulted through email $(0.9 \%)$, and sharing private information, photos, or videos on the Internet or mobile phones in a hurtful way $(0.9 \%)$

Although Model 5 had slightly lower AIC and BIC indices (Table 2), Model 4 had superior classification precision and more distinct latent classes; therefore, the four-class model was selected as optimal. This model had classification probabilities between $72.6 \%$ and $99.6 \%$ (see Table 3 ), average latent class probabilities between $86.2 \%$ and $97.2 \%$ (see Table 4), and entropy of .916 (see Table 2).

As indicated in Figure 3, C1 $(\mathrm{N}=497)$ included adolescents who experienced mostly face-to-face bullying, particularly by being called names or insulted in a hurtful way $(72.6 \%)$ and being the subject of rumours $(63.1 \%)$. Individuals in $\mathrm{C} 2$ $(\mathrm{N}=114)$ experienced mostly cyberbullying, and also reported being the subject of rumours $(69.7 \%)$. The third latent class, $\mathrm{C} 3$, was the largest $(\mathrm{N}=4,257)$, and included individuals who experienced little or no bullying and cyberbullying. Finally, C4 was the smallest latent class $(\mathrm{N}=67)$; individuals in this group experienced critical levels of both bullying and cyberbullying, particularly being the subject of rumours $(100 \%)$ and being called names or insulted in a hurtful way $(96.8 \%)$.

Results showed a significant relationship between bm and $C$ (Table 5). In reference to $C 4$, which is characterized by severe levels of victimization, as bm increases by one unit, the probability of membership increases by a factor of a) $1.882(\mathrm{t}=3.191, \mathrm{p}=.001)$ for $\mathrm{C} 1, \mathrm{~b}) 2.108(\mathrm{t}=3.175$, $\mathrm{p}=.001)$ for $\mathrm{C} 2$, and c) $2.857(\mathrm{t}=5.412, \mathrm{p}=.000)$ for $\mathrm{C} 3$. In other words, higher behaviour management effectiveness increased the probability of membership to latent classes with lower levels of victimization. Further, membership in some latent classes of $\mathrm{C}$ was associated with an increased the probability of carrying weapons to school (Table 5). Specifically, in reference to $\mathrm{C} 3$, which experienced little to no bullying or cyberbullying victimization, the probability of carrying weapons to school increased by a factor of a) $1.224(\mathrm{t}=4.337, \mathrm{p}=.000)$ for $\mathrm{C} 1$, and b) $1.202(\mathrm{t}=2.840, \mathrm{p}=.005)$ for $\mathrm{C} 4$.

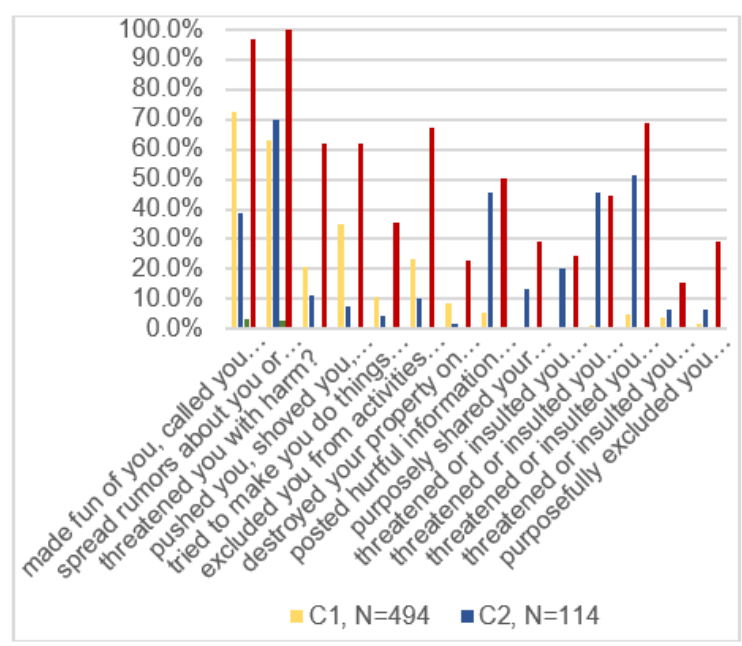

Figure 3. Item probabilities by latent class 


\section{Conclusions}

The current study identified the victimization latent classes that were most prevalent in the population of U.S. adolescents. These results may facilitate the early identification of bullying and cyberbullying victimization in schools. Results also showed that an effective behavior management at school level decreased the likelihood of being bullied and cyberbullied and, indirectly, of engaging in risky behaviors such as weapon carrying. This information is consistent with previous research on the relationship between victimization and behavior management [1, 26, 27] and is critical for practitioners because behavior management is a malleable factor, within the educators' locus of control.

Another important finding of the study is that individuals who experienced higher levels of victimization ( $\mathrm{C} 4$ and $\mathrm{Cl}$ ) were significantly more likely (by approximately 20\%) to carry a weapon to school than individuals who experienced little or no victimization $(C 3)$. This finding is consistent with previous research [40, 41, 42] and emphasizes the importance of prevention and early identification of bullying and cyberbullying. A higher incidence of weapon-carrying among adolescents has been identified as a key factor in the increase of youth violence and injury [43, 44].

\section{References}

[1] Klein, J., Cornell, D., \& Konold, T. (2012). Relationships between bullying, school climate, and student risk behaviors. School Psychology Quarterly, 27(3), 154-169. doi:10.1037/a0029350

[2] Olweus, D. (1993). Bullying at school: What we know and what we can do. Cambridge, MA: Blackwell.

[3] National Center for Educational Statistics, U.S. Department of Education and Bureau of Justice Statistics. Office of Justice Programs, U.S. Department of Justice. (2013). Indicators of School Crime and Safety: 2012 (NCES 2014-042/NCJ 243299). Washington, DC: American Institute for Research.

[4] Juvonen, J. \& Gross, E. F. (2008). Extending the school grounds? Bullying experiences in cyberspace. Journal of School Health, 78, 496-505.

[5] Anderson, M., Kaufman, J., Simon, T.R., Barrios, L., Paulozzi, L., Ryan, G., \& School-Associated Violent Deaths Study Group. (2001). Schoolassociated violent deaths in the United States, 19941999. Jama, 286(21), 2695-2702.
[6] Vossekuil, B., Fein, R.A., Reddy, M., Borum, R., \& Modzeleski, W. (2002). The final report and findings of the Safe School Initiative. US Secret Service and Department of Education, Washington, DC.

[7] Leary, M.R., Kowalski, R.M., Smith, L., \& Phillips, S. (2003). Teasing, rejection, and violence: Case studies of the school shootings. Aggressive behavior, 29(3), 202-214.

[8] Verlinden, S., Hersen, M., \& Thomas, J. (2000). Risk factors in school shootings. Clinical psychology review, 20(1), 3-56.

[9] Bilić, V., Flander, G. B., \& Rafajac, B. (2014). Life satisfaction and school performance of children exposed to classic and cyber peer bullying. Collegium Antropologicum, 38(1), 21-29.

[10] Chang, F. C., Lee, C. M., Chiu, C. H., Hsi, W. Y., Huang, T. F., \& Pan, Y. C. (2013). Relationships among cyberbullying, school bullying, and mental health in Taiwanese adolescents. Journal of School Health, 83: 454-462.

[11] Muscari, M. (2002). Sticks and stones: The NP's role with bullies and victims. Journal of Pediatric Health Care, 16, 22-28.

[12] Sourander, A., Klomek, A. B., Ikonen, M., Lindroos, J., Luntamo, T., Koskelainen, M., ... \& Helenius, H. (2010). Psychosocial risk factors associated with cyberbullying among adolescents: A population-based study. Archives of general psychiatry, 67(7), 720-728.

[13] Schoffstall, C. L., \& Cohen, R. (2011). Cyber aggression: The relation between online offenders and offline social competence. Social Development, 20, 587-604.

[14] Wagner, C. G. (2008). Beating the cyberbullies. The Futurist, 42(5), 14.

[15] Ybarra, M. L., \& Mitchell, K. J. (2004)a. Online aggressor/targets, aggressors, and targets: A comparison of associated youth characteristics. Journal of child Psychology and Psychiatry, 45(7), 1308-1316.

[16] Ybarra, M. L., \& Mitchell, K. J. (2004)b. Youth engaging in online harassment: Associations with caregiver-child relationships, Internet use, and personal characteristics. Journal of adolescence, 27(3), 319-336.

[17] Burton, K. A., Florell, D., \& Wygant, D. B. (2013). The role of peer attachment and normative 
beliefs about aggression on traditional bullying and cyberbullying. Psychology in the Schools, 50, 103115. doi:10.1002/pits. 21663

[18] Erentaité, R. Bergman, L. R., \& Zukauskiené, R. (2012). Cross-contextual stability of bullying victimization: A person-oriented analysis of cyber and traditional bullying experiences among adolescents. Scandinavian Journal of Psychology, 53, 181-190. doi:10.1111/j.1467-9450.2011.00935.x

[19] Cappadocia, M. C., Craig, W. M., \& Pepler, D. (2013). Cyberbullying prevalence, stability, and risk factors during adolescence. Canadian Journal of School Psychology, 28, 171-192.

[20] Hinduja, S., \& Patchin, J. W. (2009). Bullying beyond the schoolyard: Preventing and responding to cyberbullying. Thousand Oaks, CA: Corwin Press.

[21] Patchin, J. W., \& Hinduja, S. (2011). Traditional and nontraditional bullying among youth: A test of general strain theory. Youth \& Society, 43(2), 727751, doi: 10.1177/0044118X10366951.

[22] Werner, N. E., \& Crick, N. R. (2004). Maladaptive peer relationships and the development of relational and physical aggression during middle childhood. Social Development, 13(4), 495-514. doi:10.1111/j.1467-9507.2004.00280.x.

[23] Veenstra, R., Lindenberg, S., Munniksma, A., \& Dijkstra, J. (2010). The complex relation between bullying, victimization, acceptance, and rejection: Giving special attention to status, affect, and sex differences. Child Development, 81(2), 480-486. doi:10.1111/j.1467-8624-2009.01411.x.

[24] Wright, M.F., Li, Y. (2013). The association between cyber victimization and subsequent cyber aggression: The moderating effect of peer rejection, Journal of Youth and Adolescence, 42(5), 662-674. doi 10.1007/s10964-012-9903-3.

[25] Fredstrom, B. K., Adams, R. E., \& Gilman, R. (2011). Electronic and school-based victimization: Unique contexts for adjustment difficulties during adolescence. Journal of Youth and Adolescence, 40(4), 405-415.

[26] Allen, K. P., (2010). Classroom Management, Bullying, and Teacher Practices. Professional Educator, 34(1), 1-15.

[27] Gage, N. A., Prykanowski, D. A., \& Larson, A. (2014). School climate and bullying victimization: A latent class growth model analysis. School Psychology Quarterly. doi:10.1037/spq0000064.
[28] Nylund, K., Bellmore, A., Nishina, A., \& Graham, S. (2007). Subtypes, severity, and structural stability of peer victimization: What does latent class analysis say? Child development, 78(6), 1706-1722.

[29] Want, J., Iannotti, R. J., Luk, J. W., \& Nansel, T. R. (2010). Co-occurrence of victimization from five subtypes of bullying: Physical, verbal, social exclusion, spreading rumors, and cyber. Journal of Pediatric Psychology, 35, 1103-1112.

[30] Bradshaw, C. P., Waasdorp, T. E., \& O’Brennan, L. M. (2013). A latent class approach to examining forms of peer victimization. Journal of educational psychology, 105(3), 839.

[31] D. Lessne, M. Cidade (2015). Student Reports of Bullying and Cyber-Bullying: Results from the 2013 School Crime Supplement to the National Crime Victimizationn Survey. Web Tables. NCES 2015-056. National Center for Education Statistics.

[32] Burns, S. \& Wang, X. (2011). NCES Handbook of Survey Methods, American Institutes for Research.

[33] Brick, J.M. \& Kalton, G. (1996). Handling missing data in survey research. Statistical Methods in Medical Research, 5, 215-238.

[34] Muthén, L.K. \& Muthén, B.O. (2010). Mplus User's Guide: Statistical Analysis with Latent Variables: User's Guide. Muthén \& Muthén.

[35] Asparouhov, T. \& Muthen, B. (2012). Auxiliary variables in mixture modeling: A 3-step approach using Mplus. Mplus Web Note 15.

[36] DiStefano, C. (2012). Cluster analysis and latent class clustering techniques. Handbook of developmental research methods, 645-666.

[37] Ramaswamy, V., Desarbo, W.S, Reibstein,D.J. (1993). An empirical pooling approach for estimating marketing mix elasticities with PIMS data. Market Science, 12, 103-124.

[38] Vermunt, J.K., Magidson, J. (2002). Latent class cluster analysis. In: J.A. Hagenaars and A.L. McCutcheon (Eds.), Applied latent class analysis. Cambridge University Press, Cambridge, 89-106.

[39] Muthén, B. (2004). Latent variable analysis. The Sage handbook of quantitative methodology for the social sciences. Thousand Oaks, CA: Sage Publications, 345-68.

[40] Esselmont, C. (2014). Carrying a weapon to school: The roles of bullying victimization and 
perceived safety. Deviant Behavior, 35, 215-232. doi:10.1080/01639625.2013.834767

[41] Nansel, T. R., Overpeck, M. D., Haynie, D. L., Ruan, W. J. \& Scheidt, P. C. (2003). Relationships between bullying and violence among US youth. Archives of Pediatric \& Adolescent Medicine, 157, 348-353.

[42] Dukes, R. L., Stein, J. A. \& Zane, J. I. (2010). Gender differences in the relative impact of physical and relational bullying on adolescent injury and weapon carrying. Journal of School Psychology, 48(6), 511-532.

[43] Page, R. M. \& Hammermeister, J. (1997). Weapon-carrying and youth violence. Adolescence, 32(127), 505 .

[44] Pickett, W., Craig, W., Harel, Y., Cunningham, J., Simpson, K., Molcho, M., ... \& Currie, C. E. (2005). Cross-national study of fighting and weapon carrying as determinants of adolescent injury. Pediatrics, 116(6), e855-e863. 